\title{
Critical thinking in college students: evaluation of their beliefs in popular psychological myths
}

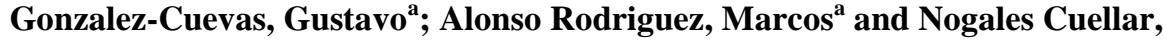 \\ Valeria $^{a}$ \\ ${ }^{\mathrm{a}}$ Department of Psychology, European University of Madrid, Spain
}

\begin{abstract}
The purpose of this study was to evaluate the degree of acceptance of psychological myths in undergraduate students in Health Sciences. Our results showed that first-year Psychology students believed more myths than did the other first-year Health Sciences students (Medicine, Dentistry, and Optics and Optometry). Third-year Psychology students drastically reduced their beliefs in myths in comparison with first-year Psychology students (Cohen's $d=1.7)$. Overall, we found a gender effect, being women less gullible than men in believing in myths. Age did not account for differences in myth acceptance. All in all, these results suggest that beginning Psychology students seem to accept more myths than other first-year Health Sciences students regarding psychological misconceptions. However, college exposure in Psychology students may favor critical thinking by diminishing myth beliefs.
\end{abstract}

Keywords: Critical thinking, psychological myths, college students 


\section{Introduction}

College students often arrive at their first introductory Psychology course with plenty of misconceptions and lack of critical thinking concerning the human mind (Lilienfeld et al, 2011). After all, the media and Internet at times present psychological information in an inaccurate and confusing way (Furnham \& Hughes, 2004), leading into widespread beliefs held contrary to known evidence, i.e., myths (Taylor \& Kowalski, 2004).

In this study, we set out to investigate whether the degree of acceptance of psychological myths varies in undergraduates students in Health Sciences, while controlling for possible confounding variables (gender and age). We also explored the resistance to modify psychological misconceptions by comparing first- and third-year Psychology students.

\section{Methods and Results}

\subsection{Methods}

One hundred and fourteen first-year undergraduate students in Medicine $(n=56)$, Dentistry $(n=50)$, and Optics and Optometry $(n=8)$ students at European University of Madrid were employed as volunteer subjects, chosen on the basis that they were taking at least one Introduction to Psychology course. An extra sample of forty-seven psychology majors was used, first- $(n=35)$ and third-year $(n=12)$ students. Our data consisted of $30.8 \%$ men and $69.2 \%$ women, ranged in age from 17 to 28 .

We chose a wide range of myths from all areas of psychology that are usually propagated in pop psychology but still present in the world of education in general. For this purpose, we adapted the questionnaire by Kowalski \& Taylor (2009) by employing a 7-point rating scale ranged from (1) strongly disagree to (7) strongly agree (see Table 1).

Statistics tests such as Pearson correlation, student t-test and ANOVA were performed when appropriated with the statistical program SPSS (version 20).

\section{Table 1. Items of the questionnaire (note that we eliminated items \#21 and \#35 in our statistitical analysis for not being psychology myths in the original test)}

1. If you're unsure of your answer while taking a test, it's best to stick with your initial hunch.

2. There are striking stylistic differences between the two hemispheres of the brain, with the left being "analytic" and the right "holistic."

3. Most people use only $10 \%$ of their brains.

4. Most "crack babies" end up with serious neurological deficits.

5. Subliminal messages can be used to persuade others to purchase products.

6. Taste areas for sweet, sour, salty and bitter are well defined on the tongue.

7. ESP (extrasensory perception) has been empirically documented.

8. During "out of body" experiences, individuals can observe themselves from above.

9. Drug education programs (i.e., DARE) are effective in deterring drug use among teenagers.

10. Individuals can learn information (e.g., new languages) while asleep.

11. During sleep, your brain rests.

12. Most people who use heroin become addicted to it.

13. Human memory works like a tape recorder or video camera, and accurately records the events we have experienced.

14. Eyewitness testimony is usually reliable.

15. Many adults were abused as children but do not remember the abuse.

16. Hypnosis is useful for retrieving memories of forgotten events. 
17. In criminal eyewitnesses, confidence is closely related to accuracy.

18. Playing classical music (e.g., Mozart) to infants and children increases their intelligence.

19. Too much sugar causes hyperactivity in children.

20. Babies who learned sign language as infants have a higher overall IQ.

21. Immediate contact between a mother and infant after birth is critical for bonding.

22. You can "spoil" a baby if you respond to its demands too quickly.

23. A baby's attachment for its mother is based on mom's filling the physiological need for food.

24. If you live long enough, you will eventually develop dementia.

25. The defining feature of dyslexia is seeing words backwards (e.g., "pal" instead of "lap").

26 . The polygraph ("lie detector") test is a highly accurate means of detecting dishonesty.

27. It is generally better to express anger openly than to hold it in.

28. Most women experience a marked worsening of their moods during the premenstrual period.

29. Raising children similarly leads to similarities in their adult personalities.

30. High self-esteem is necessary for high achievement.

31. Astrologers can predict your personality from the arrangement of stars and planets at your birth.

32. People's responses to inkblots tell us a great deal about their personalities and propensities toward mental disorders.

33. People diagnosed with schizophrenia have a split personality.

34. People who attempt to commit suicide do not talk about it.

35. We experience stress even when good things happen to us.

36. "Psychological profiling" has been shown to be an effective means of identifying criminals.

37. The suicide rate is higher among the elderly than among adolescents.

38. A large proportion of criminals are acquitted on the basis of the insanity defense.

39. Clinical judgment and intuition are the best means of combining information to reach a diagnosis for a patient.

40. A well-trained psychotherapist can establish a person's true thoughts and problems by analyzing dreams.

41. All effective psychotherapies force individuals to confront the "root" causes of their problems in childhood.

42. Electroconvulsive ("shock") therapy is a physically dangerous treatment.

43. Opposites attract: People tend to have relationships with individuals who differ from them in their personality, interests, and attitudes.

44. There's safety in numbers: The more people present at an emergency, the greater the chance that someone will intervene.

45. Women talk more than men ("Men are from Mars, women are from Venus").

\subsection{Results}

In general, our students demonstrated a high number of erroneous beliefs about psychology (Grand mean=4.58 out of 7), irrespective of their studies. However, as can be seen in Figure 1, first-year Psychology students (Total test score=220.57 out of 301) believed more myths than did the other first-year Health Sciences students (Medicine: 199.25; Dentistry: 191.60; Optics and Optometry: 191.00). Indeed, the ANOVA analysis showed that the groups differed in their mean $(\mathrm{F}=11.919, p<0.001)$ and that Psychology students differed significatively from any other group of students (Bonferroni post-hoc analysis, $p<0.001$ ). No significant differences were found between the rest of degrees, excluding Psychology $(p=N S)$. 


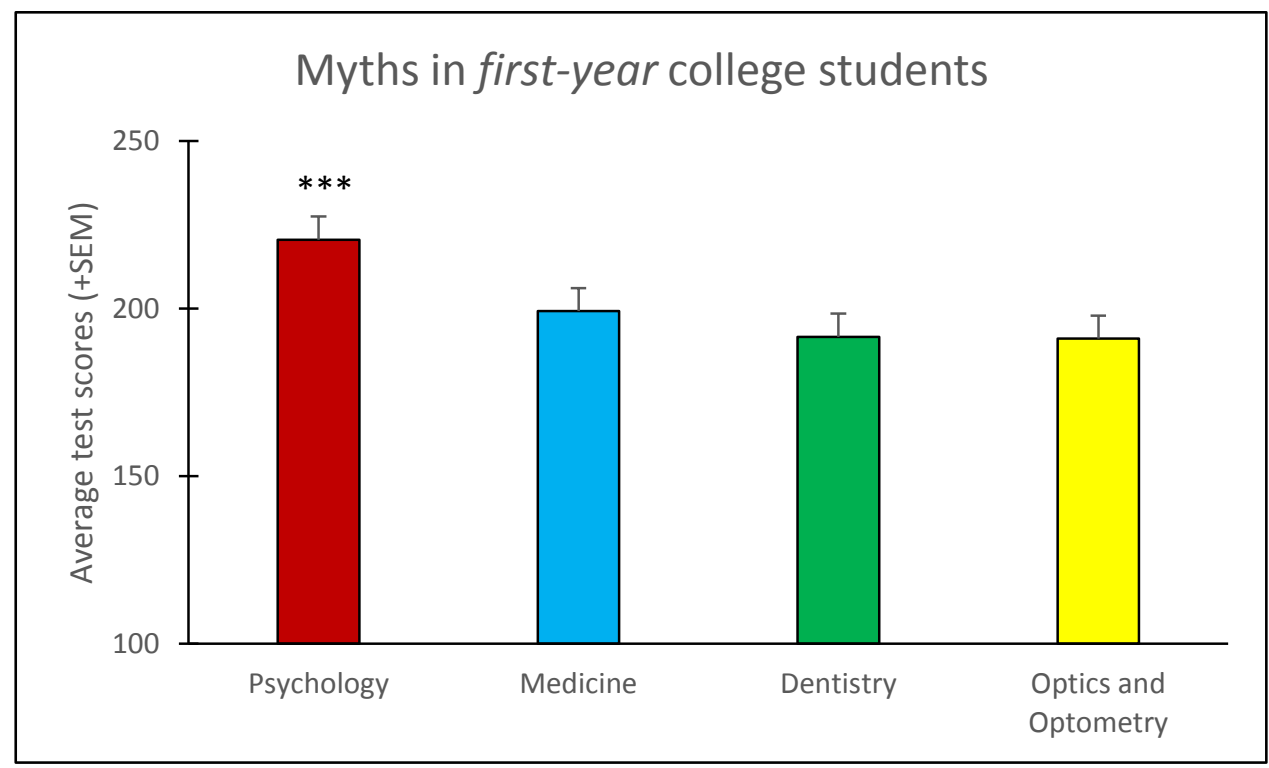

Figure 1. Believed myths in first-year college students (in average test scores). Psychology undergraduate students show significantly more beliefs in psychological myths than the other degrees (Medicine, Dentistry, as well as Optics and Optometry). No significant differences were found between the rest of degrees, excluding Psychology. *** $p<0.001$ (Psychology vs. any other degree)

As can be seen in Figure 2, Psychology undergraduate students in their first year show significantly more beliefs in psychological myths than in their third year $(\mathrm{t}=4.68, p<0.001)$. Cohen's d=1.7 indicated a strong effect size. 


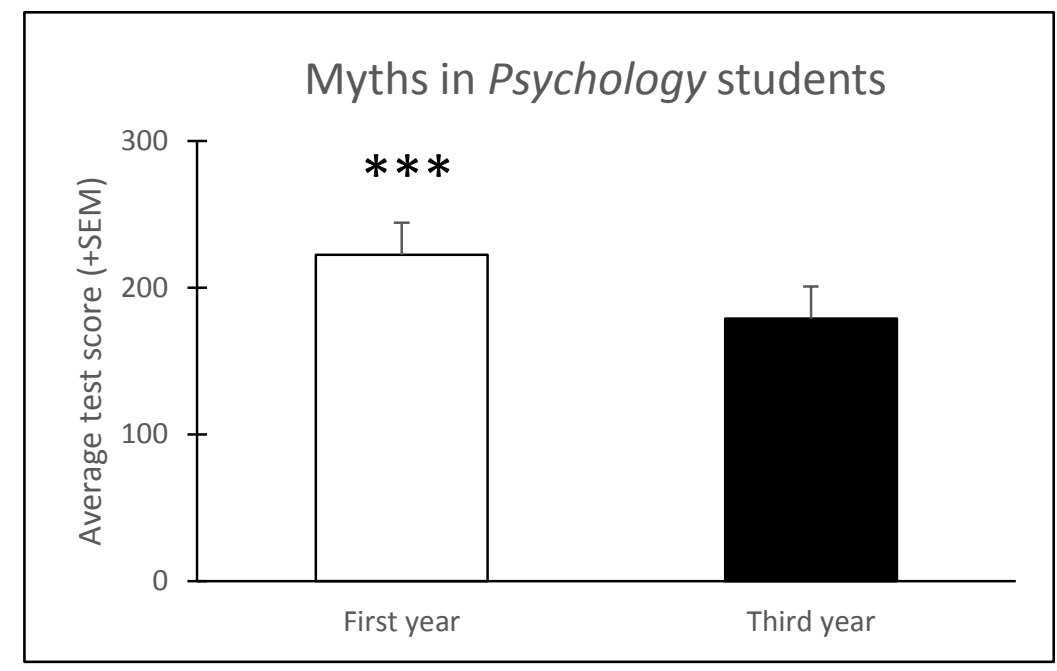

Figure 2. Believed myths in Psychology college students (in average test scores). Psychology undergraduate students in their first year show significantly more beliefs in psychological myths than in their third year. *** $p<0.001$ (First-year vs. Third-year)

Our results also showed that male Psychology undergraduate students show significantly more beliefs in psychological myths than females $(\mathrm{t}=2.56, p<0.05)$.

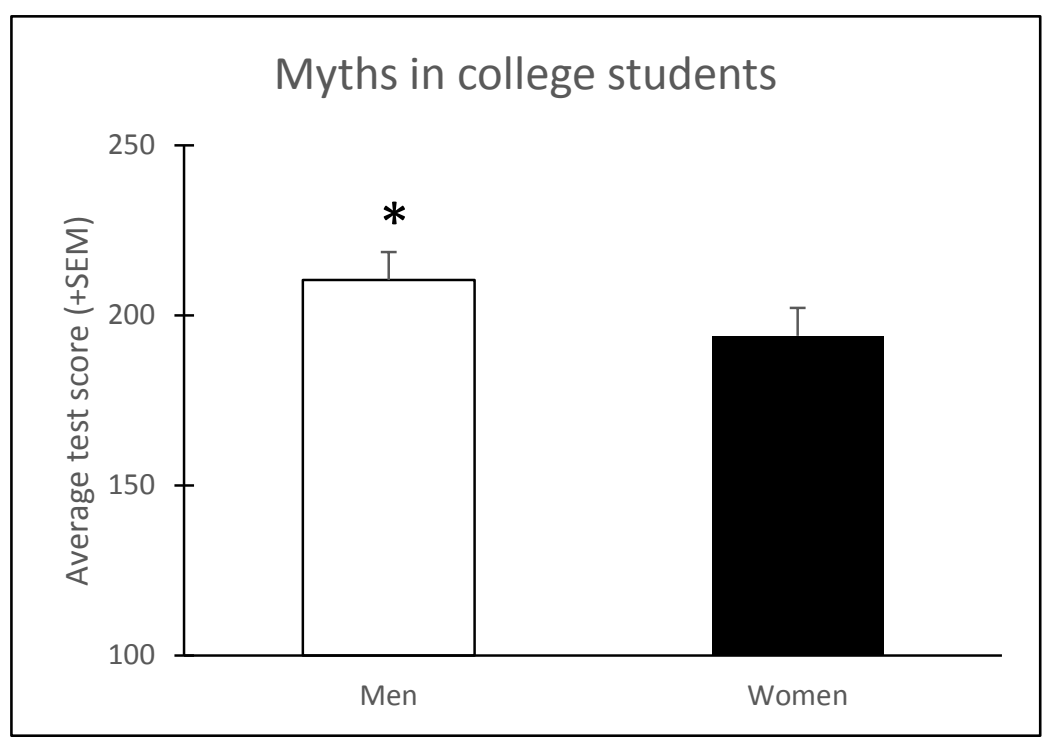

Figure 3. Believed myths in men and women college students (in average test scores). Male Psychology undergraduate students show significantly more beliefs in psychological myths than females. * $p<0.05$ (Men vs. women). 
Age, a potential confounding variable, was not related to myth acceptance, as demonstrated by a non-significant Pearson correlation analysis between the two variables $(r=0.03, p=N S)$. In table 2, we present the most common (top 3) and less common (bottom 3) myths grouped by studies. Interestingly, the most common (myth \#12) and less common (myth \#31) were, respectively, "Most people who use heroin become addicted to it" and "Astrologers can predict your personality from the arrangement of stars and planets at your birth".

Table 2. More common (top 3) and less common (bottom 3) myths in college students. The most common (myth \#12) and less common (myth \#31) were, respectively, "Most people who use heroin become addicted to it" and "Astrologers can predict your personality from the arrangement of stars and planets at your birth".

\begin{tabular}{|c|c|c|c|c|c|c|c|c|c|c|}
\hline & \multicolumn{2}{|c|}{$\begin{array}{c}\text { Psychology } \\
\text { (first year) }\end{array}$} & \multicolumn{2}{|c|}{$\begin{array}{c}\text { Psychology } \\
\text { (third year) }\end{array}$} & \multicolumn{2}{|c|}{ Medicine } & \multicolumn{2}{c|}{ Dentistry } & \multicolumn{2}{c|}{$\begin{array}{c}\text { Optics and } \\
\text { Optometry }\end{array}$} \\
\cline { 2 - 12 } & Myth \# & Mean & Myth \# & Mean & Myth \# & Mean & Myth \# & Mean & Myth \# & Mean \\
\hline \multirow{4}{*}{$\begin{array}{c}\text { Top } \\
3\end{array}$} & 12 & 6.63 & 12 & 6.45 & 12 & 6.39 & 12 & 6.14 & 4 & 6.13 \\
\cline { 2 - 12 } & 5 & 6.49 & 42 & 6.18 & 5 & 6.09 & 5 & 5.64 & 12 & 5.88 \\
\cline { 2 - 12 } & 16 & 6.18 & 4 & 6.09 & 6 & 5.89 & 6 & 5.56 & 34 & 5.75 \\
\hline \multirow{3}{*}{$\begin{array}{c}\text { Bottom } \\
3\end{array}$} & 14 & 3.80 & 43 & 2.91 & 15 & 3.55 & 15 & 3.26 & 18 & 3.00 \\
\cline { 2 - 11 } & 37 & 3.77 & 11 & 2.09 & 37 & 3.36 & 37 & 2.68 & 15 & 2.88 \\
\cline { 2 - 11 } & 31 & 3.40 & 31 & 1.55 & 31 & 1.77 & 31 & 2.42 & 31 & 2.13 \\
\hline
\end{tabular}

\section{Conclusions}

Our results revealed the existence of an alarmingly widespread high number of erroneous beliefs held by undergraduate Health Sciences students about psychology, irrespective of their particular studies; however, first-year Psychology students believed significatively more myths than did the other first-year Health Sciences students (Medicine, Dentistry, and Optics and Optometry). In this sense, beginning psychology students may be more prone to these erroneous beliefs than their counterparts due to an increased interest in psychological topics leading to an overexposure of psychological misconceptions on the media, Internet, popular psychology industry, self-help books, etc (Lilienfeld, 2005). Unfortunately, some of these students may still lack the fundamental knowledge for critical thinking thaught at university-level courses.

Third-year Psychology students drastically reduced their beliefs in myths in comparison with first-year Psychology students (Cohen's d=1.7). Although evidence for resistence to changes in psychological misconceptions may be strong (e.g., see Lokke \& Lokke, 2010), our encouraging finding is in agreement with Standing \& Huber (2003) in that the number of student misconceptions may, in part, reflect differences in the number of psychology courses taken, especially related to psychological methodologies.

Overall, we found a gender effect, being men more gullible than women into believing in myths. However, it should be kept in mind that the majority of undergraduates in health science programs are women. Furthermore, age did not account for differences in myth acceptance. All in all, these results suggest that beginning Psychology students seem to be 
in greater need of developing critical thinking skills than other first-year Health Sciences students regarding psychological misconceptions. Accordingly, college exposure in Psychology students may favor critical thinking by diminishing myth beliefs.

Importantly, undergradute students should evaluate claims in such a way that explicitly integrates basic principals of critical thinking (Lawson, 1999). Interestingly, critical thinking could be incorporated into undergraduate courses in multiple ways from problembased learning activities to solid understanding of research methods and tasks intented to "hunt" for myths. As the influential philosopher of science Karl Popper (1963) once wrote, "science must begin with myths, and with the criticism of myths."

\section{References}

Furnham, A., \& Hughes, D. J. (2014). Myths and misconceptions in popular psychology: Comparing psychology students and the general public. Teaching Of Psychology, 41(3), 256-261. doi:10.1177/0098628314537984

Kowalski, P. \& Taylor, A. (2009). The effect of refuting misconceptions in the introductory psychology class. Teaching of Psychology, 36, 153-159. doi:10.1080/00986280902959986

Lawson, T. J. (1999). Assessing psychological critical thinking as a learning outcome for psychology majors. Teaching of Psychology, 26(3), 207-209

Lilienfeld, S. O. (2005). Challenging mind myths in introductory psychology courses. Psychology Teacher Network. 15(3), 3-6

Lokke J. \& Lokke G. (2010). On misconceptions about behavior analysis among university students and teachers. The Psychological Record. 60, 325-336.

Lilienfeld, S. O., Lynn, S. J., Ruscio, J., \& Beyerstein, B. L. (2011). 50 great myths of popular psychology: Shattering widespread misconceptions about human behavior. John Wiley \& Sons.

Popper, K. R. (1963). Conjectures and refutations. The growth of scientific knowledge (Essays and Lectures). Routledge \& Kegan Paul.

Standing, L. G., \& Huber, H. (2003). Do psychology courses reduce belief in psychological myths?. Social Behavior and Personality: an international journal, 31(6), 585-592.

Taylor, A. K., \& Kowalski, P. (2004). Naive psychological science: The prevalence, strength, and sources of misconceptions. The Psychological Record. 54, 15-25. 